\title{
CROP GROWTH \\ AND AVAILABILITY OF MOISTURE
}

\author{
W. C. VISSER
}

\section{INTRODUCTION}

The evidence discussed in this paper has been gained in a country where $60 \%$ of the land relies entirely on drainage, either because of its situation below sea level or because it would, were it not for good water management, be flooded by the rivers. The higher ground consists mostly of glacial sands with low water-retaining capacity. Interest in recent years has been centred on raising productivity by draining water from wet areas, and also by supplying dry regions with water.

The drainage problem in the Netherlands is centuries old, but water supply is a recent problem. On podsolised soils the supply of plant nutrients, has been the most urgent problem for many years, but now that the supply of artificial manure is adequate, water is gradually becoming the limiting physical factor in the increase of production.

Scientific work on productivity showing the influence of water as a growth factor started in the Netherlands about 15 years ago. The first approach dealt with the excess of water, although data concerned with lack of water were also collected. In this way statistical data were compiled as to the significance of the groundwater table at shallow as well as lower depths.

New aspects of research into the significance of water have been tackled in the last two years. The investigations concerning the influence of moisture conditions on crop rotation - although interesting-will not be dealt with here, nor will the very recent trials, aimed at the determination of the influence of moisture on labour requirements on the farm.

Scientists in the Netherlands pay to-day more attention to the effect on growth of moisture tension than to moisture flow, but this attitude is changing gradually. The growth of crops can be related to static conditions of the moisture situation but also to more dynamic conditions. Yield in relation to depth of the groundwater table is a far more static concept than the relation between yield and evaporation.

Water table management studies started in early times when people took an interest in the relation between the water level in the ditch and the crop yield. The first scientific research was done on the relation between groundwater table and the level in the ditch. The next step was to visualise the water table as a potential at a depth where no plant roots grow. The use of the soil moisture potential in the root zone itself as a productivity characteristic seemed to be a better approach. This investigation into the relation between crop yield and the tension in the root zone involved a parallel study on the relation between depth of groundwater and moisture potential in the root zone.

Evaporation as an explanatory characteristic for crop yields was next studied. If evaporation is used as a characteristic, the problem of moisture uptake under the influence of a shallow water table, as in the catchment areas of the Netherlands 
polder area, becomes identical with the moisture problems of water uptake of deeply drained, unsaturated profiles which occur with sprinkling irrigation. The relation between the moisture tension in the root zone and the flow of the water in the plant and in the capillary zone is then the separate investigation that has to be executed parallel to the yield studies to cover the whole problem.

Water movement and productivity raise the question of steady and non-steady movement. Time is a factor in these problems on the flow of water and a parallel can be seen between this group of flow problems in hydrology and the investigations concerning the critical period for the application of water in yield studies.

The attempt to define the moisture problem more and more precisely, leads to a task of an immense complexity. This task has not yet been completed and we are forced to work on a catena of problems much more complex than the simple and directly applicable problems of groundwater level and crop response studied some years ago.

In the present work attention is drawn to the steady growth of the study on the availability of water and the gradual replacement of empirical principles by more fundamental ones.

The statistical treatment is being gradually replaced by the functional, the concept of moisture tension by that of moisture flow, and consideration of steady conditions by that of non-steady conditions.

\section{CROP GROWTH AND GROUNDWATER DEPTH}

The reaction of the crop to groundwater depth has attracted much attention, as depth of the water table is the simplest available characteristic.

Some experimental fields were constructed, but the majority of the results were derived from observation plots scattered over the area of investigation. The influence of other growth factors, which might obscure the reaction function for moisture, can be eliminated by a graphical-statistical method.

The simplest curve, without any interaction of other factors, is shown in Fig. 1. The curve shows a wet part where a higher water table would be harmful, an intermediate section where the depth of the water table is nearly optimal and a third part where water is in short supply. The shape of these curves changes with altering moisture conditions, with climate, crop and profile. The wet part of the curve is least affected by these factors.

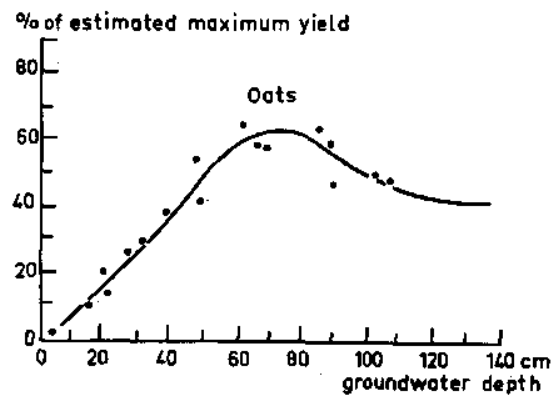

Fig. 1.

GeNERAL SHAPE OF THE CURVE FOR WATER DEPTH AND YIELD OF CROP

The optimal water depth depends on the fineness of the soil, the yield at deep water levels on the moistureretaining capacity 


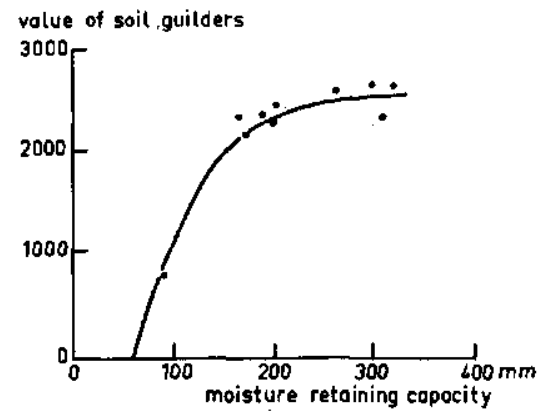

FIG. 2.

GENERAL SHAPE OF THE CURVE FOR MOISTURE-RETAINING CAPACITY AND YIELD FOR DEEP LEVELS OF GROUNDWATER

Instead of yield, the vertical axis shows the value of the soil in guilders. This has been done to level the influence of rainfall variations which may change the significance of the moisture-holding capacity of the soil with respect to the quantity of readily available water

Fig. 2 shows how the profile influences the yield at the dry portion of the curve in Fig. 1. If the moisture-holding capacity of the soil varies, the yield in the horizontal part of the dry section of the curve varies according to a curve of the type shown in Fig. 2. The best profiles of good clay soils in the Netherlands, used as arable land, or the soils used for some types of horticulture, hardly show any depression due to deep groundwater because of their high water-holding capacity. On dry profiles the decrease of the yield may however be very large.

If the water-holding capacity of a soil is high, the fineness of the soil particles is often greater than that of a soil with lower water-retaining capacity. This correlation means that, with deep water tables, for soils with a good moisture-holding capacity, the capillary contact between plant roots and groundwater table remains sufficient. This is not the case for drier soil types with a coarser texture.

In Fig. 3 curves are given for a number of profile groups of the soil map of the Netherlands, covering all the profiles distinguished by Dutch soil scientists. In this figure, there is a strong correlation between the yield at a deep water table and the water-holding capacity of the soil. With good water-holding capacity the decrease in yield is small, with a small water-holding capacity this decrease becomes rapidly larger. The correlation between the two quantities seems to be very high. We know, however, that this relation is not as close as given in Fig. 3. A number of minor influences may change this relation. Lack of precise knowledge about the properties of the profiles made only a first approximation possible. The curves of Fig. 3 were

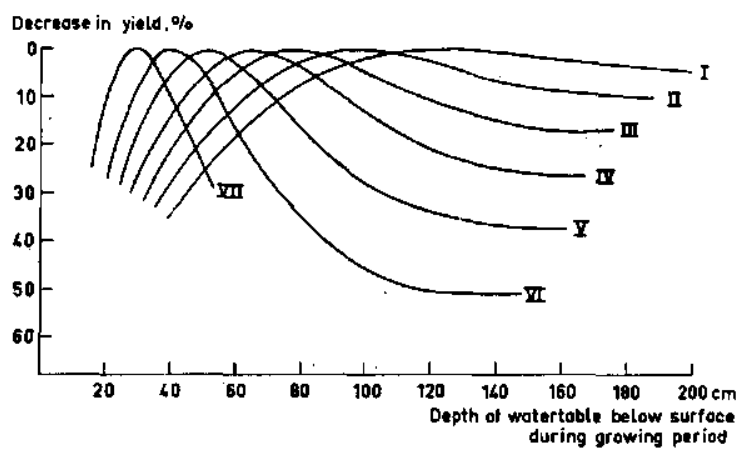

FIG. 3.

RELATION BETWEEN DECREASE OF YIELD AND DEPTH OF WATER TABLE DURING GROWING SEASON

The units of the soil map of the Netherlands were grouped in seven classes to which the curves I-VII were assigned, referring to the use as permanent grassland or arable land. From these curves the drainage requirements, in a survey covering the whole of the country, were determined 


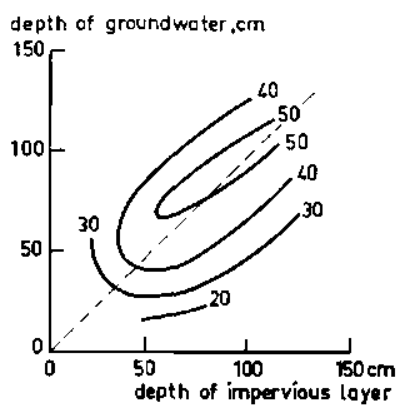

FIG. 4.

RELATION BETWEEN THE YIELD, GIVEN BY CURVES OF EQUAL RELATIVE PRODUCTIVE CAPACITY, AND A COMBINATION OF DEPTH OF AN IMPERVIOUS LAYER IN THE SOIL AND DEPTH OF GROUNDWATER

Many factors influence the shape of the curves for water depth and yield. The principal influence is exerted by impervious layers in the profile

used for an inquiry into the state of water management over the whole agricultural area of the Netherlands, for which some simplification was needed anyway.

A large number of growth factors influences the shape of the curve for the relation between water depth and crop yield. There is hardly any combination of factors with an interaction-value equal to zero. The $\mathrm{pH}$ seems to have perhaps the slightest influence. An important factor, which modifies the growth curve considerably, originates from discontinuities in the profile, such as hard-pans. In Fig. 4 the influence is shown of an impermeable layer in a clay soil at varying depths. The curves of equal yield show that the water level should not be lowered beyond the impermeable layer.

In the study of the influence of groundwater level, the lowering of the water level during the growing season appears to be gradual and very similar from year to year.

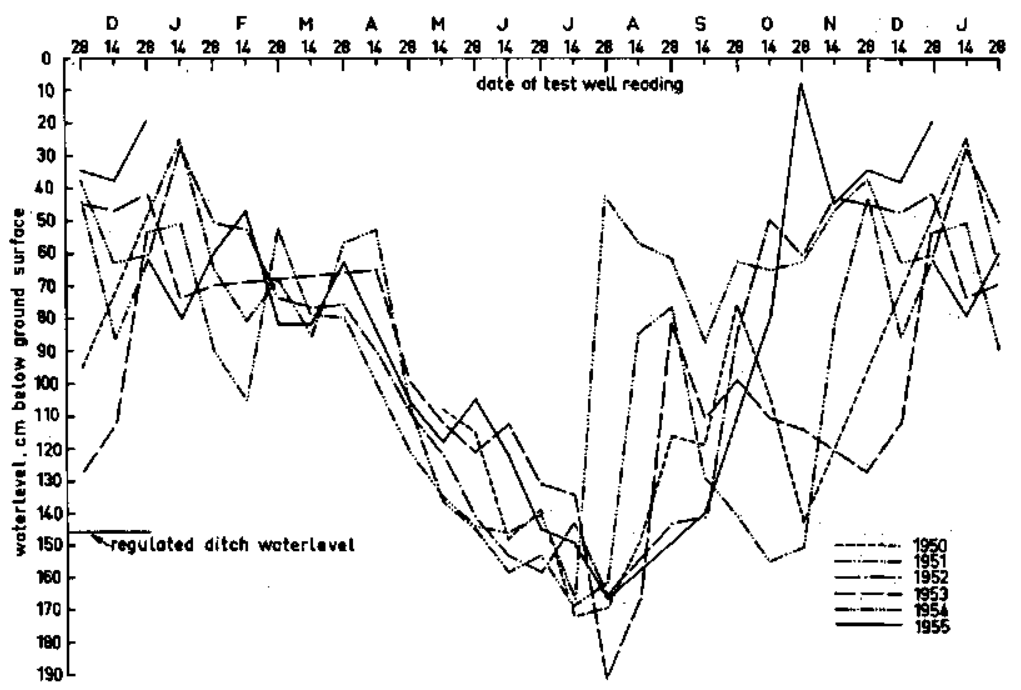

Fig. 5. WATER LEVEL AT DIFFERENT PERIODS OF THE YEAR

Readings of test wells during 5 years show the similarity of the decrease in water level from December to June. Variations occur mostly in autumn. Two determinations of the water depth, one in winter and one in summer, are sufficient to give with fair accuracy the water depth at any required date within the growing period 
The groundwater depth was plotted against time for a fair number of test wells, and curves of the type of Fig. 5 were obtained. With the Netherlands climate a parallel fall of the water table in different years during spring and early summer may be expected. The rise in autumn may take place in different months, this may be as early as June, or the deep water level may remain until December or even later.

The last factor studied was the variation in the water level during the year. The growth of a crop is a non-steady problem and the time factor cannot be excluded from a study on the response of crops to moisture availability.

The growth of the crops coincides therefore with this gradual lowering of the water table and this decrease may be characterized with good accuracy as the difference between the summer and winter groundwater depth.

By pooling all the available data and the existing conceptions with regard to the yield - water depth relation, it was possible to design curves for equal yields for varying winter and summer water tables. Fig. 6 gives a diagram for the third group of soil profiles of Fig. 3. with medium moisture-holding capacities Attention should

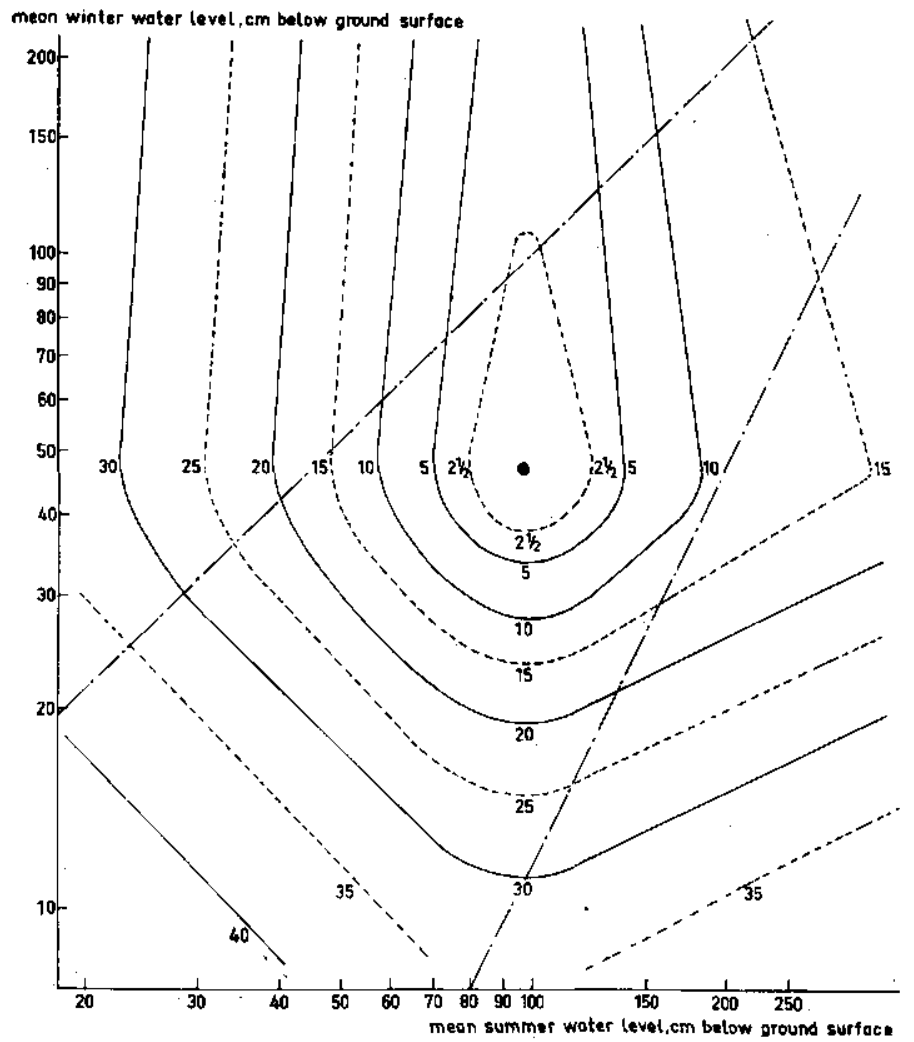

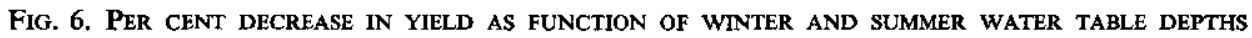
SHOWING LINES OF EQUAL DECREASE

The two oblique straight lines give the limits between which the water table is generally situated. These isocarp diagrams were constructed for the seven soil mapping units mentioned in Fig. 3 
be drawn to certain points. The water depth in winter has to be rather shallow as deep water tables then appear to be somewhat harmful. The reason for this is not clear, but the downward trend in crop yields for the same depth of water in summer and increasing depth in winter is well established.

The effect of the lowering of the water table during the spring and summer for various soil profiles has been studied for ten years. The diagram (Fig. 6) is the most elaborate description of the growth function of moisture yet obtained. After this static approach was worked out, the conception of the characterization of soil moisture shifted to other descriptive facets, i.e. the more dynamic characterization of the moisture conditions. The isocarp diagrams represent the only completely worked out directive for water management.

\section{CROP GROWTH AND WATER TENSION}

In consequence of the work done on the capillary forces of soil moisture, the depth of the water table was more and more looked upon as the depth of the plane with zero moisture tension. This conception resulted logically in a new description of the problem of the crop reaction on moisture conditions. The investigations were directed towards the relation between water tension in the root zone and yield. The availability was regarded as a function of the suction force. A few examples of this are given below.

In Fig. 7 the results of the yearly shoot growth of fruit trees in relation to the soil moisture tension show how BuTIN (1957) proves that growth is retarded on drier

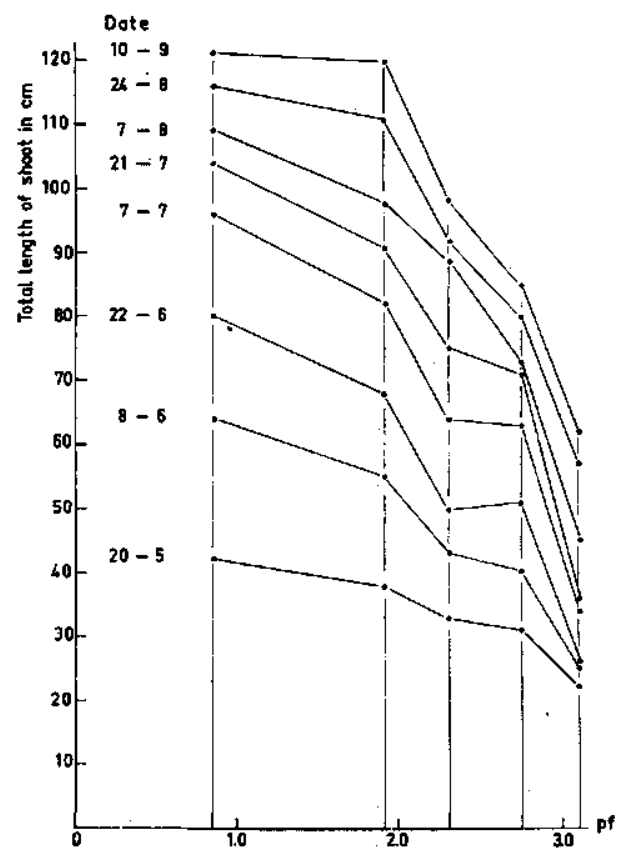

Fig. 7.

PF DURING PERIOD OF GROWTH AND SHOOT LENGTH OF FRUIT TREES

The shoot length is often used as a measure of the productivity. It is clear that the shoot length reacts favourably on a rather high moisture content of the top soil (after BuTIJN, 1957) 


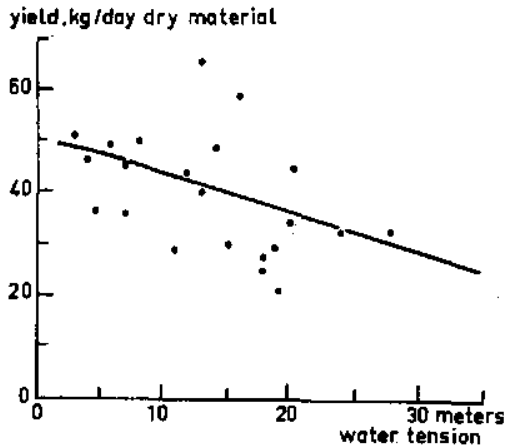

FIG. 8.

RELATION HETWEEN GRASS YIELD AND WATER TENSION

Grass growth is severely hampered by high water tension, but many other factors may interfere in this relation (after MAKKINK, 1955)

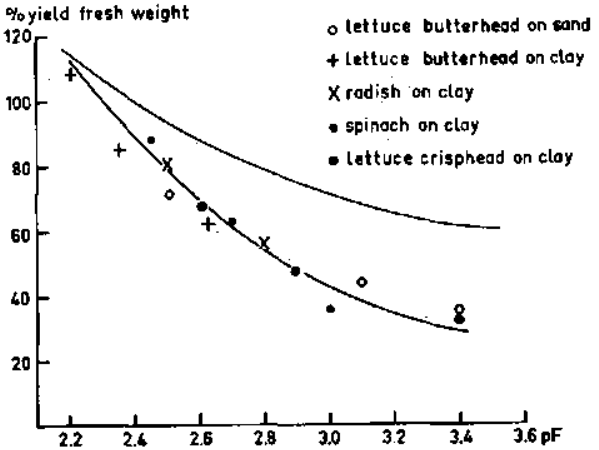

FIG. 9.

RELATION BETWEEN PF AND YIELDS OF VEGETABLE CROPS GROWN IN POTS ON SAND AND CLAY UNDER CONTROLLED MOISTURE CONDITIONS. UPPER CURVE: AUTUMN YIELD, LOWER CURVE: SPRING YIELD (AFTER BIERHUIZEN AND DE VOS, 1958)

The individual points of the upper curve were omitted, as the variation was nearly equal to that of the lower one.

soils. The indications of critical periods are not very strong and the curves appear to be of one and the same type with only a difference in the vertical scale. From other work it also appears that a critical period does in many cases not exist if the $\mathrm{pF}$ is taken as the moisture characteristic, where it would have been found if the amount of sprinkling water had been taken as the moisture indicating characteristic.

In Fig. 8 a different view on the problem is given, where the yields of grass for different lysimeter pots with sand, clay and peat soil are plotted against the moisture tension in metres water column. Other growth factors disturb the relation to some extent. The conclusions of MAKKINK (1955), based on extensive tests, that there is no clear influence of the profile on the growth function for grass, support the idea that the data for the moisture tension correlate well with the theoretical magnitude for the basic growth-factor water.

An even better proof of the value of the soil moisture tension as an indicator for the availability of water is drawn from the work of BIERHUIzen and DE VOS (1958) with pot cultures. They show that within narrow limits no difference exists in the observations of yields of various horticultural crops grown on sand or clay. Fig. 9 gives some results of their work.

It is not surprising that these results strongly support the view that the soil moisture tension is a basic factor for plant growth. The plant has to compete with the capillary effect of the soil and the nearer the two capillary forces, of suction by the plant and retention by the soil, approach each other, the lower the yield will be. At pF 4.2 the plant reaches its maximum capillary action and at this degree of dryness the plant fights a losing battle.

This theory is supported by investigations on the amount of water evaporated by 


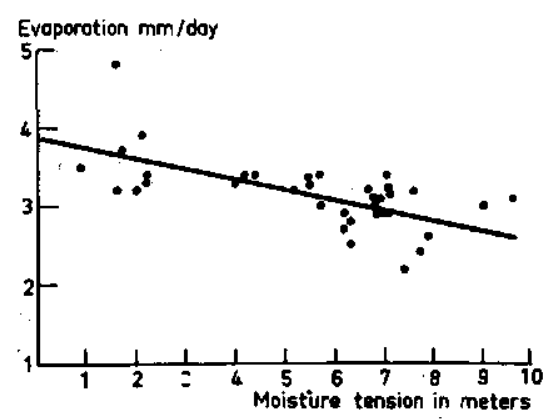

FIG. 10.

RELATION BETWEEN EVAPORATION OF A LYSIMETER TANK AND THE MOISTURE TENSION OF THE TOP LAYER (AFTER MAKKINK AND VAN HEEMST, 1956)

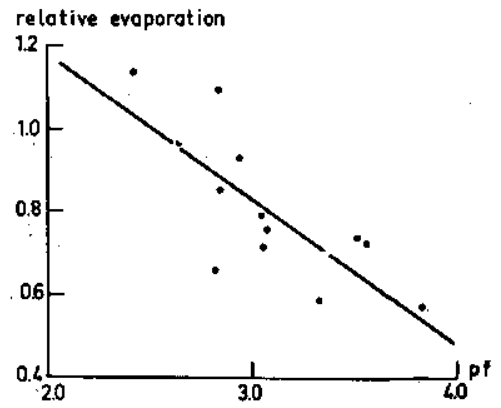

Fig. 11.

ReLATIVE EVAPORATION (eVAPORATION CALCULATED AFTER PENMAN AS UNITY AND $\mathrm{pF}$

There is reason to believe that the straight line should run somewhat steeper than this set of readings indicate (after WIND, 1955)

soil and plant, as a function of the soil moisture tension. MAKKINK and VAN HEEMST (1956) obtained the results shown in Fig. 10, where the evaporation of a lysimeter is plotted against the water tension in the root zone in metres water column. WIND (1955) gives other results, shown in Fig. 11, for evaporation plotted against pF. The straight-line relation holds in both diagrams true only for a limited part of the moisture tension scale. The points in Fig. 11 diverge rather from the line drawn, and if a steeper curve were drawn the points would, except for the three at the right, be nearer to the new line. Fig. 11 gives zero evaporation at a rather high $\mathrm{pF}$, so that the steeper curve seems more probable. Both sets of results show clearly that evaporation decreases on drier soil.

Closer examination of these evaporation results does not necessarily support the theory of the basic significance of the moisture tension, but they point to the signifcance of moisture movement. The significance of moisture for growth is not only a function of a static soil condition but may also be a dynamic function of moisture flow.

\section{CROP GROWTH AND EVAPORATION}

The investigations of the last few years, many of them still unpublished, have been made to ascertain the significance of evaporation as a measure of the availability of water. These studies were only possible when the value of the evaporation calculation according to PenMAN (1948) was fully recognised.

WIND (1957) gave, in studies on the yield of grass plots, the relation between the yield and the calculated evaporation; reduction of the potential evaporation was taken into account if dessication of the profile made this necessary. The grass yields did show a fair relation with the evaporation data, given in Fig. 12 for peat soils.

The simplicity of this relation makes the result quite convincing provided that one 


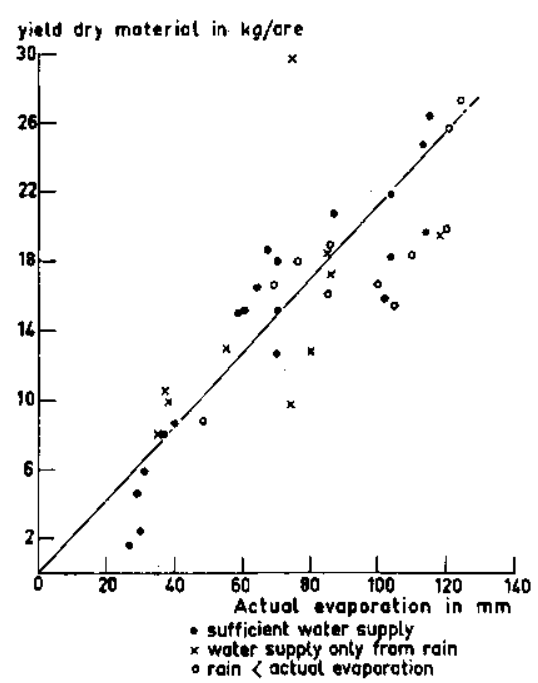

FIG. 12.

GRASS YIELD OF A NUMBER OF FIELD EXPERIMENTS PLOTTED AGAINST THE ACTUAL EVAPORATION

The yield appears to be a linear function of the evaporation during the time of growing between two cuts (after WIND, 1957). Experiments on Zuid-Holland peat

accepts water as a material that the plant needs in direct proportion to its own weight. This however, is not the generally accepted point of view, the latter being that water is necessary for regulation of the temperature of the plant. It should not be forgotten that the energy balance is proportionally nearer to the area which is covered by the crop than to the weight of the crop.

DE WIT (1958) studied the relation between crop yield and evaporation on results from irrigation field experiments in the United States and developed further the theory of evaporation as a basic moisture characteristic. His idea is that both evaporation and crop growth are a function of radiation and that evaporation is not governed by factors other than radiation and moisture tension. The production of plant material however is a function not only of water but also of other growth factors. When the yield reaches the level where other growth factors become limiting, the evaporation may still increase although the crop yield remains the same. Fig. 13 gives an instance of this.

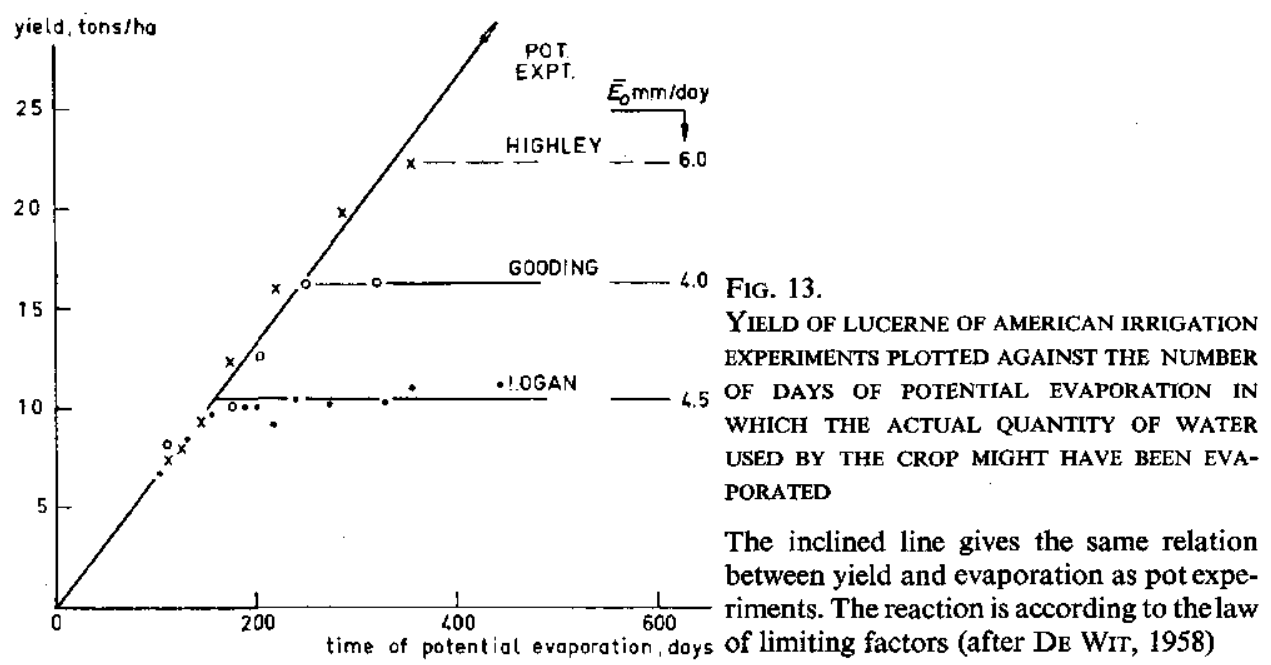




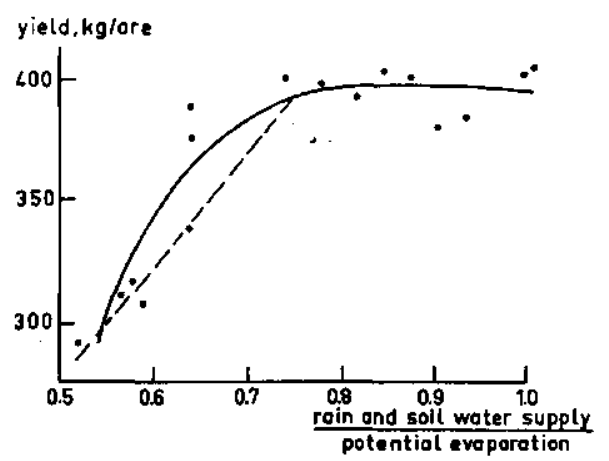

FIG. 14.

Yield OF POTATOES OVER A PERIOD OF 16 YEARS PLOTTED AGAINST THE RATIO OF RAIN PLUS SOIL WATER SUPPLY TO POTENTIAL EVAPORATION

The curve of the Mitscherlich type may well be replaced by the dotted curve of the type of the law of limiting factors as in Fig. 13 (after VAN DuIN and SCHOLTE UBING, 1955)

If there are no other factors limiting crop growth, the relation between water consumption and dry yield is found equal to the relation for pot experiments. This finding links the old biological conception of a fixed relation between crop yield and evaporation with the physical conception of evaporation according to the energy balance.

Proof of this theory can be seen from the results of other investigators such as VAN DUIN and ScholTE UBING (1955) if the growth curve of the Mitscherlich type is changed to a growth function for limiting factors (see Fig. 14). These authors, using potato yields of different years, plotted the relation between rainfall and soil moisture and the calculated evaporation according to PENMAN (1948). The diagram shows that the evaporation in excess of $75 \%$ of the possible one is not used for production of dry material or at least does not coincide with an increase in production.

The results of a pot experiment of PeERLKAMP and GoEdewaAgen (1957) given in Fig. 15, however, indicate that hasty conclusions should not be drawn where results are not as pleasing or simple as those just given. Large containers which were shielded from rain were used to grow crops. The experiment started with different groundwater levels and the amount of water used could be related to the yield.

In the diagram with logarithmic scales the curves do not coincide, showing that the relation is more complex than can be given by means of the law of the limiting factors. The irrigation trials which DE WIT (1958) used aimed at keeping the moisture

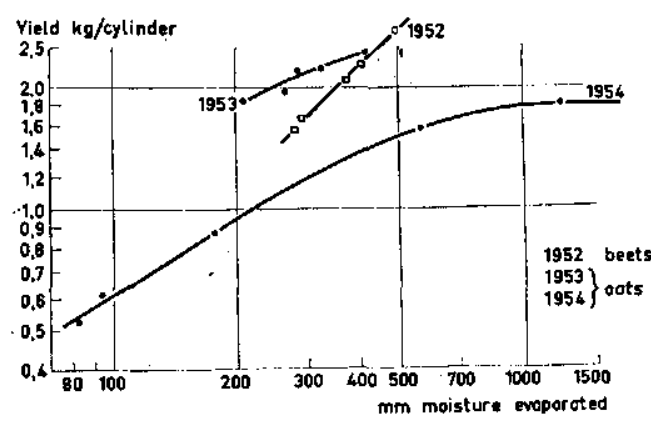

FiG. 15.

RELATION BETWEEN YIELD AND EVAPORATED MOISTURE

Experiments in big culture cylinders where, after good growth was obtained, the plants were shielded from rain. In essentially non-steady moisture conditions the yield curves for different years do not coincide, making it very uncertain that the law of limiting factors also holds under these circumstances (after Peerlkamp and Goedewaagen, 1957) 
conditions constant and were of a steady type. The experiment of PeErlKamp and GOEDEWAAGEN (1957) on the contrary was designed to exhaust the water in the soil and was of a non-steady type.

In hydrology, with steady flow, storage capacity has no effect, but with non-steady flow it is an important factor. With plant growth it can also be expected that the number of factors governing a non-steady state will be larger than the numbers for a steady flow. These additional factors account for the divergence of the curves from the pattern for limiting factors.

\section{THE AVAILABILITY OF WATER AND THE PHYSICAL CONDITION OF THE SOIL}

It is rather surprising that good results can be obtained irrespective of which of the following moisture characteristics has been employed: (1) depth of water table and moisture-holding capacity, (2) pF values, (3) amount of evaporated water.

That a good relation is possible between crop yield and these widely divergent moisture characteristics suggests a mutual correlation existing between them in the field. It also suggests for practical projects the use of whatever factor seems most fitting to the problem.

The functional relations between these moisture data, found in the soil during the year, must in reality be very complicated. The aim of the investigations in the Netherlands is to construct a mathematical model for moisture profiles and capillary flow, that may reproduce those situations in the soil which occur with a reasonable frequency and connect water depth, tension and evaporation. Work has been done in a number of countries on this moisture distribution and flow (see papers by KLUTE (1952), PhILIP (1957), ChILDs (1957) and others). The numerical solutions derived, are not easily incorporated in a general expression for crop production and are only useful for highly specialized work.

If these expressions for the moisture situation in the soil at a given moment have to be handled by people with a main interest in agricultural problems instead of in soil physics, a solution as a formula or a nomograph is more practical.

The formula for capillary flow may be derived from the differential equation:

$$
\frac{\delta \mathrm{q}}{\delta \mathrm{t}}=\frac{\delta}{\delta \mathrm{z}}\left\{\mathrm{k}\left(\frac{\delta \psi}{\delta \mathrm{c}} \cdot \frac{\delta \mathrm{c}}{\delta \mathrm{z}} \pm 1\right)\right\}
$$

where $\delta \mathrm{q} / \delta \mathrm{t}$ is the velocity of the streamflow, $\delta \psi / \delta \mathrm{c}$ is directly related to the $\mathrm{pF}$ curve, the quotient $\delta \mathrm{c} / \delta \mathrm{z}$ represents the differential of the moisture content over the

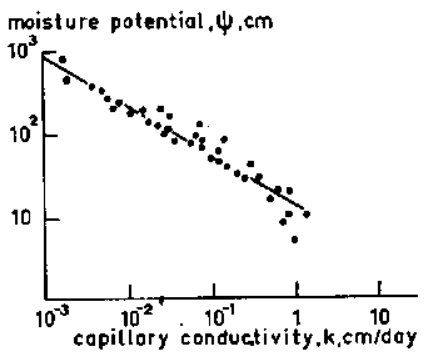

FIG. 16.

RELATION BETWEEN CAPILLARY CONDUCTIYITY AND THE MOISTURE POTENTIAL ON LOGARITHMIC SCALES 
profile, while $\mathrm{k}$ is the capillary conductivity, governed by the potential of the soil moisture.

From investigations by WIND (1955) and Wesseling (1957), it follows that a linear relation between $\log \mathrm{k}$ and $\log \psi$ holds sufficiently well over a long range of $\psi$ values as is depicted in Fig. 16. Then $\mathrm{k}$ becomes

$$
\mathrm{k}=\mathrm{a} \psi^{\mathbf{n}}
$$

Investigations into the nature of the $\mathrm{pF}$ curve have shown that the relation between moisture content and capillary force is not so simple and the formula has not yet been checked sufficiently to be substituted in the solution of the differential equation. An empirical formula, that was checked for a wide variety of soils is shown in Fig. 17. This formula, the simplest of a number of formulas that were tried, does not lead to

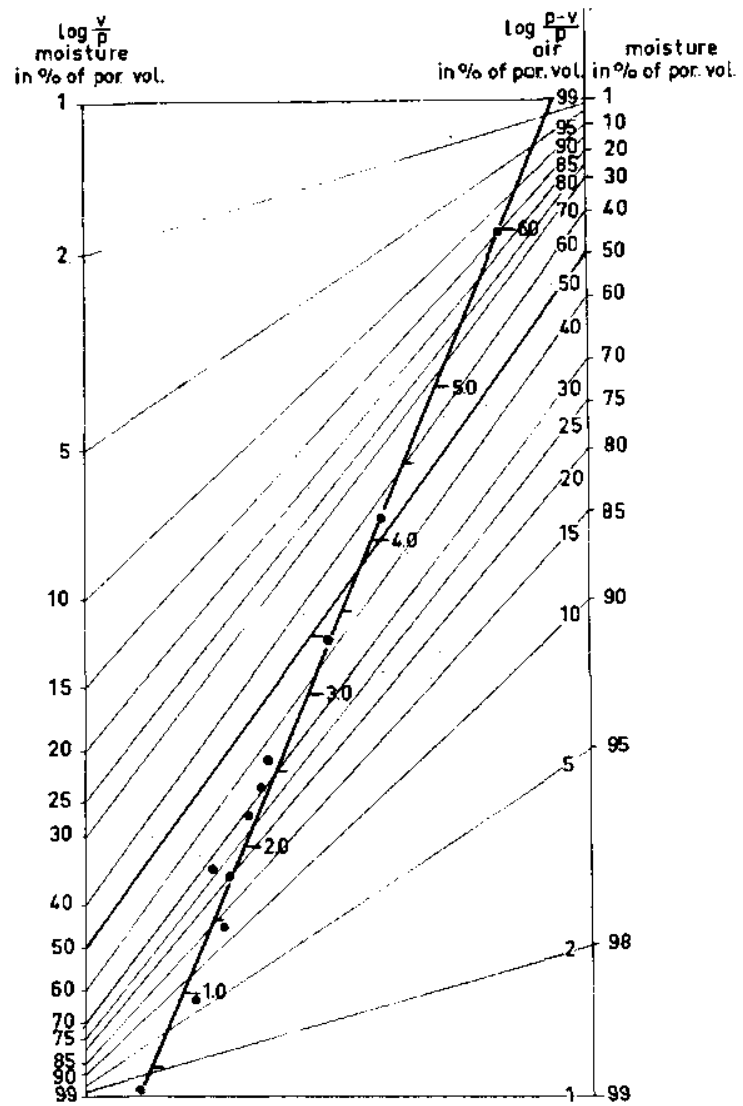

Fig. 17. Relation BETWEEN pF (Diagonal aXis) AND PER CENT SATURATION OF PORE SPACE

The moisture characteristic curve of a soil sample may be depicted by a curve of the type

$$
\frac{\mathrm{pF}+\mathrm{b}}{\mathrm{pF}_{\mathrm{o}}+\mathrm{b}} \cdot \frac{\mathrm{A}}{\mathrm{A}+\mathrm{B}}=\frac{\log \mathrm{c}-\mathrm{A}}{\log \mathrm{c}(1-\mathrm{c})-(\overline{\mathrm{A}}+\mathrm{B})} ;
$$

In the formula $\mathrm{pF}$ and $\mathrm{c}$ are the analytical results, the other symbols representing soil constants. In the graph, $\mathrm{v}$ is the moisture content, $\mathrm{p}$ the pore space 
a simple solution of the formula for capillary flow. Further investigations are needed to find the basic relations to solve the non-steady flow of capillary moisture.

The model for steady flow is easier, requiring solution of the equation:

$$
\mathrm{dZ}=\frac{\mathrm{d} \psi}{\left(\mathrm{v} \psi^{\mathrm{n}} / \mathrm{D}\right) \pm 1},
$$

where $\mathbf{Z}=$ depth of water table

$$
\begin{aligned}
& \psi=\text { potential } \\
& \mathbf{v}=\text { velocity of capillary flow } \\
& \mathbf{D}=\text { constant, approximately equal to permeability of saturated soil } \\
& \mathbf{n}=\text { soil constant }
\end{aligned}
$$

In this equation the value of the exponent $\mathrm{n}$ may vary between 1.5 and 3.0 . The solution for the upward flow of capillary moisture is the most important for the study of the availability of water and is found by taking the positive sign in the equation.

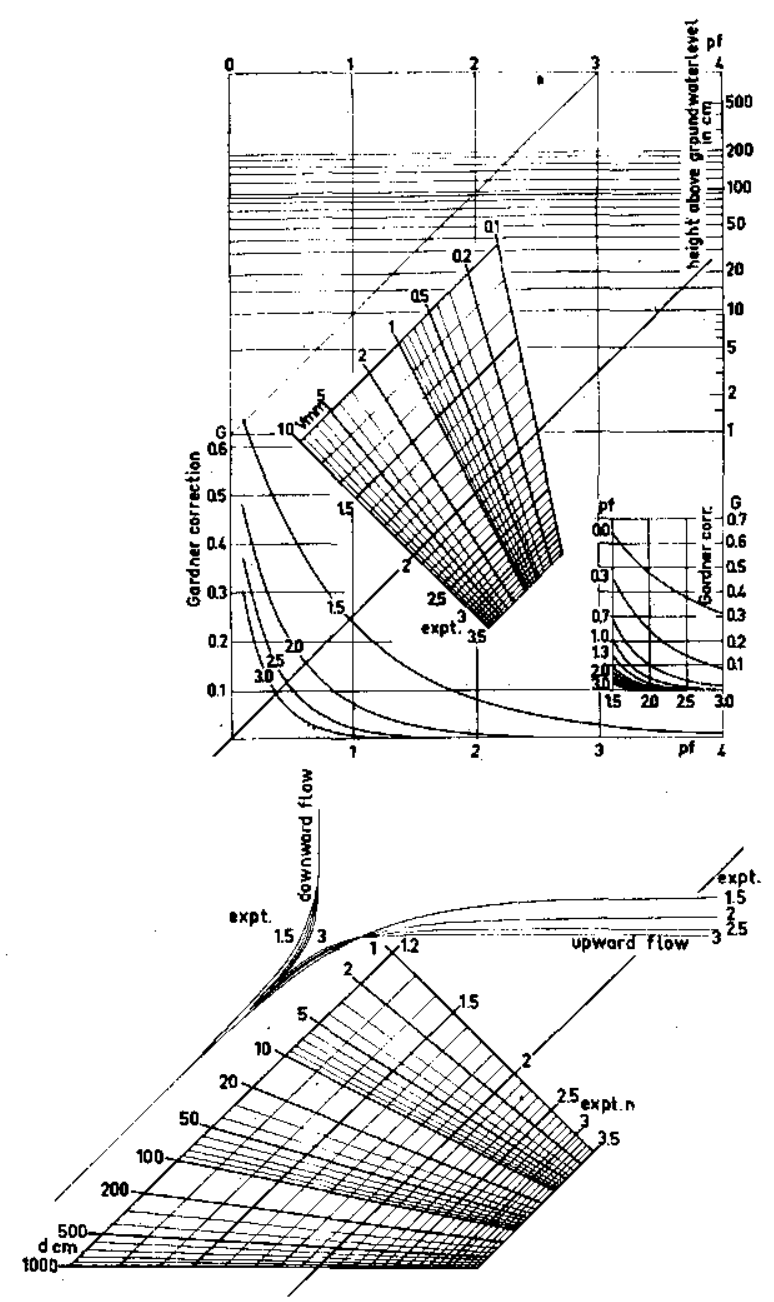

As the formula becomes unwieldy for values of $\mathrm{n}$ differing from 2, a nomograph was designed consisting of two parts. The lower diagram in Fig. 18 gives a number of curves of a rather similar shape. The upper diagram gives horizontally the $\mathrm{pF}$-axis and vertically the axis for the groundwater depth log $Z$. By placing the curves in the right position with regard to the origin, the relation between height above the groundwater table and the $\mathrm{pF}$ is found. The exact position of the two diagrams with regard to each other is governed by the velocity $v$ of the capillary flow, the exponent $\mathrm{n}$ and the permeabil-

FIG. 18.

NOMOGRAPH FOR SOLUTIONOF STEADY CAPILLARY FLOW.

If the checker-boards of the two diagrams are put upon each other in the right way, then the curved lines from the lower diagram give the relation between the $\mathrm{pF}$ and the groundwater depth, plotted on the $z$ axis of the upper sheet for values $n, v$ and $d$ chosen on the checkerboards 


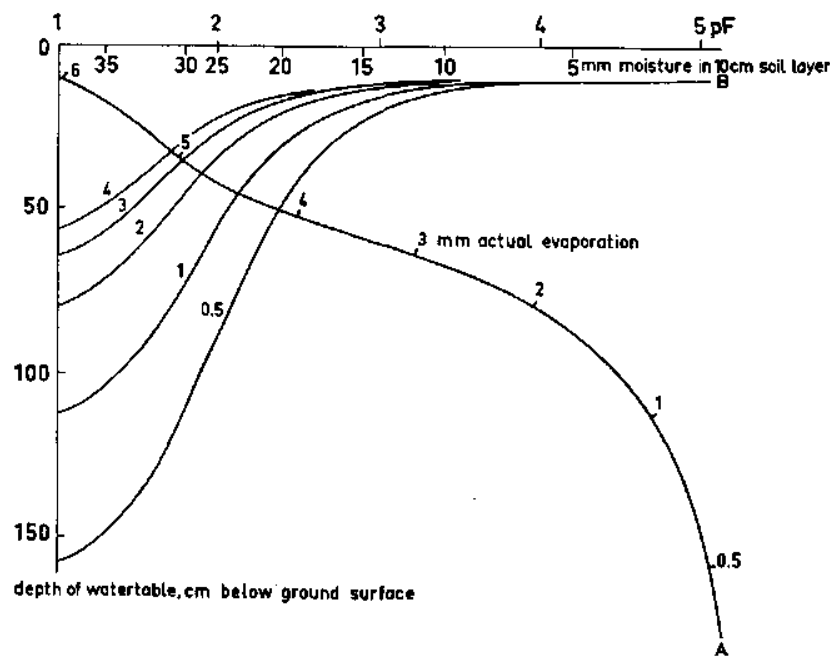

Fig. 19.

THE RELATIONS SHOWN IN FIGS. 11 AND 18 COMBINED, GIVE THE CAPILLARY FLOW FOR A CHOSEN VALUE OF THE POTENTIAL EVAPORATION

Such a calculation gives in curve A the infiuence of the lowering of the water table on the $\mathrm{pF}$ in the root zone. The curves $B$ give the $\mathrm{pF}$ for different heights in the profile for a chosen depth of the water table

ity $\mathrm{d}$ of the nearly saturated soil. The points $\mathrm{n}, \mathrm{v}$ and $\mathrm{n}, \mathrm{d}$, that represent the situation in study, are chosen on the two checker-boards. If the two sheets are laid upon each other and these two points coincide and if the axes on both sheets run parallel, then the relation between $\mathrm{pF}$ and $\mathrm{Z}$ is obtained that belongs to the selected combination of $n, d$ and $v$ by reading the $Z$ and $p F$ which match with respect to the curve for $n$. A correction according to GARDNER (1958) can be applied.

This model for steady flow gives a first approximation for the moisture relations in the soil. When the more difficult problem of the non-steady flow is solved, this solution of steady flow will have only limited importance. From this model, however, a deeper insight into the relation between the crop yield and the moisture characteristics can be gained.

Fig. 19 shows the relation between the depth of the groundwater table and the $\mathrm{pF}$ - or the moisture content - for a daily potential evaporation of $4 \mathrm{~mm}$. The relation between the potential and the actual evaporation is taken from Fig. 11.

For the centre of the root zone - here assumed to be at a depth of $20 \mathrm{~cm}$. - a relation between the $\mathrm{pF}$ and the depth of the water table is represented by curve $\mathrm{A}$. The curves $\mathrm{B}$ give the change in $\mathrm{pF}$ - or in the moisture content in the profile - from the water table to the root zone. The wilting point is reached for this soil at $5 \%$ moisture.

An evaporation of 2 to $3 \mathrm{~mm}$. a day would require a depth of the water table of 65 to $60 \mathrm{~cm}$. and a pF of 3.4 to 4.0 . According to Fig. 14 this would mean a yield between 70 and $100 \%$. Now we know that for this type of soil the optimum yield is obtained by a water depth of $70 \mathrm{~cm}$. From comparison with the curves of Figs. 7, 8 or 9 , it is clear that the $\mathrm{pF}$ is too high for optimum yield, which means that the curve in Fig. 11 in reality runs somewhat steeper.

For steady flow, the fixed relation which exists between the $\mathrm{pF}$, the evaporation and the depth of water in the soil, gives qualitative results which are in harmony with the results of the experiments on crop response. The results in an absolute sense do 
not yet compare well. If data are used which suppose a stronger increase in evaporation per unit of $\mathrm{pF}$ - in this case a steeper line in Fig. 11 - the actual evaporation in Fig. 19 would approach zero at a lower value of the $\mathrm{pF}$. This would be more in accordance with the existing experience.

Consideration should not only be given to the non-steady flow of moisture, but also to the possibility that the plant can bring the plane of mean moisture extraction to a lower level. It may be deduced from the model that below this plane an increase of moisture flow will be experienced by the plant at an increasing depth.

Under dry conditions the mean level of water uptake of the root system will shift undoubtedly in the direction of the deeper roots, which can extract the water more easily than the more shallow ones. The potential of the root system to extract water at different depths and the influence of the difference in activity at various depth zones of the root system is, however, still the weaker link in the sequence of successive moisture relations. WIND (1955) did show that the depth of the mean uptake of water may be found, by proving that below this plane, the water moves according to the laws of motion in the partly filled capillaries of the soil. Above this plane the Poisseuille law is followed, which governs the flow of water through entirely filled capillary tubes such as are found in roots. This type of investigation needs further expansion if the problem of availability of water for the plant is to receive a firm biological as well as a hydrological support.

\section{SumMarY}

The inquiry into the best method to characterize the water requirements of the crop started with the study of the depth of the water table in the soil and the moistureholding capacity of the profile. The suction force of the water in the root zone was taken later to give a better description of the availability of water. The investigations shifted in a still later stage from potentials to moisture flow as a basic factor and evaporation was looked upon as the value which governed plant growth. $\mathrm{pF}$ and evaporation, however, are influenced by the moisture characteristic curve of the profile and by the magnitude of the deviation of the moisture content from the moisture characteristic curve in case capillary movement of water is present. The availability of water in the profile is not a simple property and a more generally applicable theory will have to use a complicated function of a number of moisture characteristics.

Non-steady flow is the aspect of moisture flow which most affects the availability of water in the ground. Further research on the effectiveness of one single moisture value appears to be of limited usefulness and three-- or four-value characteristics will give a better description. The plant, however, will be able to adjust itself to the moisture conditions of the soil. The pattern of moisture flow is such, that a slight change in depth of the water may cause a marked change in the availability of moisture. The influence of plant roots on the uptake of water will be far from negligible. This part of the investigation has not yet received the attention it deserves.

The investigations into water as a growth factor started as a rather simple problem, but now it is seen to be complex. The ultimate solution will therefore have to be divided into various methods of varying complexity and probably inversely varying 
accuracy. It will have to be recognized that a less accurate method, which is simpler to use, may be of greater value than an accurate solution.

The study of the availability of water for plant growth seems to approach the point where further detail becomes of questionable practical significance and seems to have entered into its most difficult stage, where the simplification of results rather than the determination of governing principles is the main problem.

\section{REFERENCES}

Bierhuizen, J. F., and N. M. DE Vos. 1958. Report Conference Supplemental Irrigation, Com. VI, I.S.S.S., Copenhagen. Inst. Cultuurtechn. en Waterhuish., Wageningen: 83

Butiun, J. 1957. Private communication

ChIlds, E. C. 1957. Rapp. Congr. int. de la Sci. du Sol (Paris) B: 265

Duin, R. A. H. van, and D. W. Scholte UBing. 1955. Landbouwk. Tijdschr. 67: 795

Gardner, W. R. 1958. Soil Sci. 85: 228

KLuTE, A. 1952. Soil Sci. 73: 105

MakKInK, G. F. 1955. Landbouwk. Tijdschr. 67: 713

_- and H. D. J. VAN Heemst. 1956. Neth. J. agric. Sci. 4: 67

Peerlkamp, P. K., and M. A. J. Goedewaagen. 1957. Private communication

Penman, H. L. 1948. Proc. roy. Soc, A 193: 120

Philip, J. R. 1957. Aust. J. Phys. 10: 29

Wesseling, J. 1957, 'Water government in agricultural Soils', Doctoral thesis, Wageningen. (The Hague: Staatsdrukkerij)

WIND, G. P. 1955. Neth. J. agric. Sci. 3: 60

- 1957. Private communication

WIT, C. T. DE. 1958. Versl. Landbouwk. Onderz. 64, 8 